\title{
Underwater cryotrap-membrane inlet system (CT-MIS) for improved in situ analysis of gases
}

\author{
Torben Gentz and Michael Schlüter
}

Alfred Wegener Institute for Polar and Marine Research, Am Handelshafen 12, D-27570 Bremerhaven, Germany

\begin{abstract}
Membrane inlet sensor techniques allow online, real-time and in situ analyses of gases during the investigation of aquatic environments. Of specific interest for research and applied objectives are quantifications of gases like methane, higher hydrocarbons, carbon dioxide, nitrogen, volatile organic compounds, and pollutants. For these objectives, membrane inlet systems are coupled to optical or solid state sensors as well as mass spectrometers. Besides the gases of interest, large quantities of water vapor are passing through the membrane and are thus introduced into the sensor system. This downgrades the detection limit, affects the ionization efficiency of mass spectrometers, or could cause the condensation of water within infrared sensors. In this study, we describe a novel robust, low-power cryotrap coupled to a membrane inlet system (CT-MIS), which is suitable to be used in harsh environments, including underwater applications. The entire system is of small size and weight, is operated at $-85^{\circ} \mathrm{C}$, and requires an energy consumption of less than 10 Watt. By using the cryotrap, we are able to reduce water vapor in the analytical line by more than $98 \%$. The detection limits for major and trace gases are considerably improved this way. For the trace gas methane $\left(\mathrm{CH}_{4}\right)$, the detection limit was lowered from 100 to $16 \mathrm{nmol} / \mathrm{L}$, which allows the measurement of methane in surface and bottom waters of coastal areas and lakes. In case of membrane failure, the CT-MIS acts as a security system by shock-freezing the water, thus blocking the capillary connection to the analyzer unit.
\end{abstract}

The analysis of gases like carbon dioxide $\left(\mathrm{CO}_{2}\right)$, methane $\left(\mathrm{CH}_{4}\right)$, higher hydrocarbons, dimethylsulfide (DMS), as well as volatile organic compounds (VOCs) in marine or freshwater environments, has been gaining attention as an increasing necessity within the last few years. Such gases are produced in the water column or released from sediments as well as anthropogenic sources. Examples for the release of gases from sediments are seeps, mud volcanoes, or pockmarks, which are observed along coastal margins, as well as in lakes (Hovland and Judd 1988; Milkov 2000). At such sites, analyses of gases

*Corresponding author: E-mail: torben.gentz@awi.de; phone + 49471 48312029 /-fax 1425

\section{Acknowledgments}

The authors are grateful to Erich Dunker for technical support and advice during manufacturing the CT-MIS. The authors thank the captain and the crew of R/V Heincke for their assistance during several cruises. We are indebted to Roi Martinez for the GIS support. Sabine Kasten, Michiel Rutgers van der Loeff, and Aysel Sorensen are thanked for helpful comments on the manuscript. The research leading to these results has received funding from the European Community's Seventh Framework Programme (FP/2007-2013) under grant agreement nr 217246 made with the joint Baltic Sea research and development programme BONUS.

DOI 10.4319/lom.2012.10.317 like $\mathrm{CH}_{4}$, higher hydrocarbons or natural $\mathrm{CO}_{2}$ are required to be performed to calculate budgets, evaluate the fate of gases due to microbial turnover processes, as well as estimating the air-sea exchange of trace gases (Hovland and Judd 1988; Leifer and Boles 2005b; McGinnis et al. 2006, 2011; Niemann et al. 2005; Rehder et al. 1998; Sahling et al. 2008; Sauter et al. 2006; Suess et al. 1999; Tortell and Long 2009). Furthermore, economic demands related to geo-engineering issues, for example, require onsite and online gas analyses to monitor the release of $\mathrm{CH}_{4}, \mathrm{CO}_{2}$, or VOCs from underwater pipelines, wells, or geological sequestration sites (Camilli et al. 2009; Leifer and Boles 2005a; McMurtry et al. 2005).

For the investigation of gas concentrations in aquatic systems, techniques like water sampling by e.g., Rosette Sampler, subsequent phase separation by head space technique, as well as analyses by gas chromatography are well established (Kampbell et al. 1989). Unfortunately, these procedures are rather time consuming. Especially for settings where steep concentration gradients exist, for example at seeps or pockmarks, they limit the spatial resolution by which concentration fields can be described.

Furthermore, at sites where high gas concentrations are observed, the decompression of water samples during the sampler retrieval on board the vessel could cause a loss of gases 
(Schlüter et al. 1998). Such restrictions stimulated the development of continuous underway measurement systems (Butler and Elkins 1991; Gueguen and Tortell 2008; Johnson et al. 1999; Saltzman et al. 2009; Tortell 2005) and underwater gas analyzers for in situ measurements of $\mathrm{O}_{2}$ (Oxygen), $\mathrm{CH}_{4}$, VOCs, and $\mathrm{CO}_{2}$ (Boulart et al. 2008; Camilli and Hemond 2002; Emerson et al. 2002; McMurtry et al. 2005; Prien 2007; Short et al. 2006b; Wankel et al. 2010).

Whereas optodes for in situ measurement of $\mathrm{O}_{2}$ rely on a chemical transducer and measurement of fluorescence, most other underwater gas analyzers require a gas extraction unit. Most of these units apply membrane inlet systems (MIS), which allow the phase separation of gases like $\mathrm{CO}_{2}, \mathrm{CH}_{4}, \mathrm{DMS}$, radon, or VOCs from water into the gaseous phase (Boulart et al. 2010; Johnson et al. 2000; Prien 2007). The gas phase separated by the MIS is introduced into an analytical unit, like a mass spectrometer, gas chromatograph, infrared spectrometer, or solid-state gas sensors for detection of the composition of the gas mixture as well as gas concentrations.

Dependent on the field of application, research as well as industrial applications make use of different membrane materials and geometries (e.g., planar, tubular, or coiled) when performing phase separation with membrane inlet systems. These membranes are made of polydimethylsiloxane (PDMS), Teflon (Teflon, AF2400) as well as materials like Nafion, Celgard, or Accurel (Melin and Tautenbach 2006). Common to these different materials are their nonporous or microporous properties, which are impermeable to the liquid phase, up to a certain pressure. The transfer of gases through solid state membranes like PDMS as well as Nafion, or through microporous membranes like Accurel or Celgard, is described and modeled by concepts like permeation or pervaporation. A detailed consideration of different membrane materials and separation mechanisms, considering analytical as well as industrial application, is provided by Melin and Tautenbach (2006).

The mass transport of gas through a membrane depends on the membrane type as well as the specific properties of the gas. Most of the nonporous or microporous membranes are hydrophobic and preferentially exclude the polar water molecules over, e.g., VOCs. However, they do not completely exclude water vapor $\left(\mathrm{H}_{2} \mathrm{O}_{\mathrm{v}}\right)$, and because it is the matrix, it is still the major gas species in the vacuum system (Tortell 2005). The $\mathrm{H}_{2} \mathrm{O}_{\mathrm{v}}$ affects gas analyses done by mass spectrometry, as well as the IR bands of the analyte during spectroscopy, downgrades the detection limit, or could cause condensation of water inside the optical sensor section of the analyzer.

Regarding membrane inlet mass spectrometry (MIMS), additional disadvantages of high water vapor contents within the vacuum line are excessive pressure in the ion source of the mass spectrometer and decreased signal stability at $\mathrm{Ar}$ (argon, $\mathrm{m} / \mathrm{z} 40), \mathrm{O}_{2}(\mathrm{~m} / \mathrm{z} 32)$, and $\mathrm{N}_{2}$ (nitrogen, $\mathrm{m} / \mathrm{z} 28$ ), for example (Bell et al. 2011; McCarthy and Gardner 2003; Tortell 2005).

In the laboratory, interferences due to a high amount of water vapor entering the sensor system can be avoided by absorbing agents (e.g., Dierite), molecular sieves, or cold traps. The detection limits for, e.g., VOCs, DMS, $\mathrm{CH}_{4}$, or DMSP (dimethylsulfoniopropionate) are considerably improved by enriching, and subsequently releasing, analytes within the cryotrap (Damm et al. 2008; Desmarais 1978; Mendes et al. 1996a; Simmonds 1984). For the measurement of some analytes, the trapping of gases like water vapor or hydrogen sulfide $\left(\mathrm{H}_{2} \mathrm{~S}\right)$ improves the signal-to-noise ratio, the detection limit, and the measurement precision (Kolb et al. 1996; Mendes et al. 1996b).

Compared to cryotraps applied in laboratories, issues like small size, low weight, small waste-heat production, robustness, and especially low energy consumption are the required specifications in underwater applications. This article describes the design and performance of a novel underwater cryotrap membrane inlet system (CT-MIS), reaching temperatures of less than $-85^{\circ} \mathrm{C}$ to trap water vapor before entering the analytical line. The CT-MIS is self-contained, and with small modifications, can be coupled to different optical sensors in addition to mass spectrometers. For the assessment of the CTMIS, the unit was coupled to the underwater mass spectrometer (UWMS) InSpectr200-200 (Bell et al. 2007, 2011; Short et al. 2001, 2006a; Wenner et al. 2004). We applied this system in the Baltic Sea and the North Sea for the analysis of $\mathrm{Ar}, \mathrm{O}_{2}$, $\mathrm{N}_{2}, \mathrm{CH}_{4}$ as well as $\mathrm{CO}_{2}$ in the water column and also at the sediment-water interface.

For trapping water vapor from the gas phase before a chemical analysis using gas chromatography, MIMS, or IR spectrometry cryotraps of different types are applied. The design varies from U-shaped type capillaries submerged in Dewar flasks to advanced microjet cryotrap systems (Desmarais 1978; Kolb et al. 1996; Peters and Yakir 2010; Van Der Laan-Luijkx et al. 2010). Techniques to cool down a section of the gas stream include the application of liquid $\mathrm{N}_{2}$ or Ar contained in Dewar flasks and thermoelectric cooling by Peltier elements or high performance cryopumps. The cooling temperature depends on the mode of operation as well as the freezing point of the gases of interest. For example, to trap water vapor in a vacuum section (i.e., @0.0533 Pa $=4 \times 10^{-4}$ Torr) while connecting a membrane inlet system with a mass spectrometer, the cryotrap has to be operated at a temperature of about $-80^{\circ} \mathrm{C}$ (Wexler 1977).

For the application of cryotraps in laboratories, features the evaporation of cooling agents as well as size and weight of the device are of minor importance. In contrast, these features are essential for cryotraps, which are applied on research vessels or mounted in pressure housing for the use in underwater applications. In such applications, the use of cooling agents such as liquid ethanol or $\mathrm{N}_{2}$ would lead to the formation of large gas volumes and could cause security risks or are inappropriate during operation.

Therefore, from a technical as well as analytical perspective, the following issues are considered mandatory for a standalone underwater cryotrap membrane inlet systems: (1) tem- 


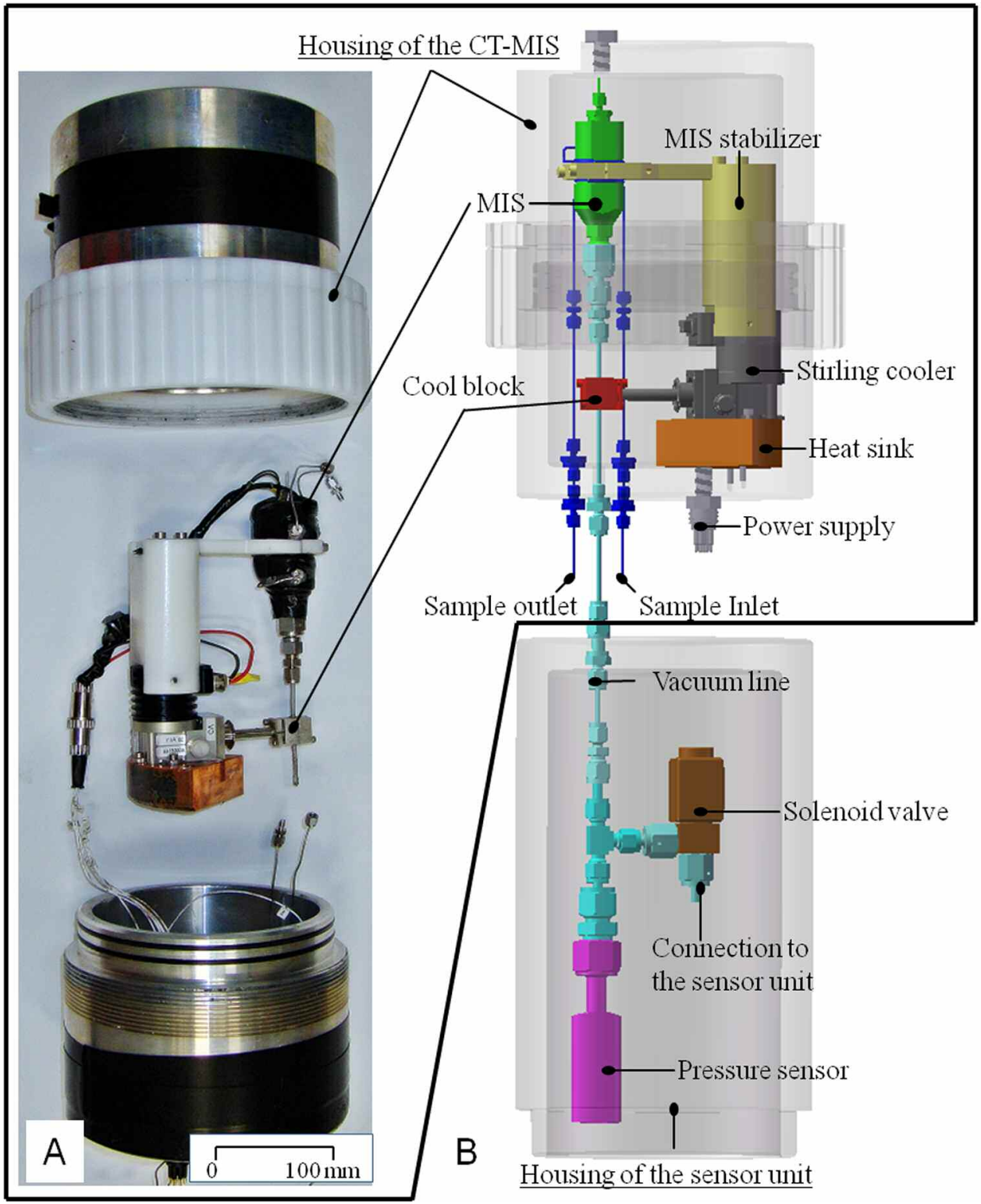

Fig 1. (A) Image of the disassembled pressure housing (depth rate up to $200 \mathrm{~m}$ ) and schematic drawing of the cryotrap membrane inlet system (CTMIS). Main components of the CT-MIS are the Ricor cooler (K508) and the membrane inlet system (Short et al. 2001). (B) Schematic drawing of the lower part of the sensor housing including the Pirani pressure sensor (PSG502-S, Inficon) and the solenoid valve (EVI $005 \mathrm{M}$, Pfeiffer vacuum).

peratures below $-85^{\circ} \mathrm{C}$ have to be reached, (2) a small wasteheat production is required, (3) the energy consumption has to be below $10 \mathrm{~W}$, (4) a service lifetime of more than $10 \mathrm{~h}$ is favorable, (5) a short cool-down time below $60 \mathrm{~min}$ is necessary, and (6) the system should be robust, of small dimensions, and low weight for applications in harsh environments.

\section{Materials and procedures}

Because small-sized, low energy, robust mechanical designs as well as liquid-free cooling systems are required, we considered the application of Stirling coolers and Peltier elements. Due to the low energy consumption, Stirling coolers would be a suitable choice for the application in underwater cryotraps. Peltier elements are inexpensive, do not contain moving parts, and are small and of low weight, which are beneficial features for applications in harsh environments. Potential drawbacks of Peltier elements are the high electrical energy consumption as well as the high waste-heat production.

For the development of an underwater cryotrap, we compared a compact Stirling cooler (Ricor $1 / 2 \mathrm{~W}$ Micro Stirling Cooler K508; Fig. 1B) with an advanced three-layer Peltier cooler (Whatson Marlow, MI4040) able to generate temperature differences of up to $120^{\circ} \mathrm{C}$. The $\mathrm{K} 508$ is a rotary compressor with a mechanically driven expander. Under ideal condi- 
tions (operating in a vacuum at an ambient temperature of $20^{\circ} \mathrm{C}$ ), a temperature of $-196^{\circ} \mathrm{C}$ is reached. Even under standard conditions (operating in air at an ambient temperature of $20^{\circ} \mathrm{C}$ ) temperatures of less than $-93^{\circ} \mathrm{C}$ were achieved. The weight of the K508 is about $450 \mathrm{~g}$, and the dimensions are 116 $\times 58 \times 71 \mathrm{~mm}$. The results of the Stirling cooler and the Peltier element are shown in more detail in the "Assessment" section.

The cold part of the Stirling cooler is coupled to a $1 / 8$-inch capillary tube by an aluminium block of $20 \times 20 \times 20 \mathrm{~mm}$ (Fig. $1 \mathrm{~B})$. The water vapor will be trapped in the inner part of this capillary tube. The block is divided in two parts, which are connected by screws to clamp down the capillary tube. The heat sink of the cooler is coupled to a copper block, which is tightly connected to the inside of the pressure housing (Fig. 1B). The area of the copper block connected to the pressure housing measures about $4550 \mathrm{~mm}^{2}$. This is sufficient for the heat to transfer from the cooler inside the pressure housing to the outside, and to minimize any warming of the interior of the pressure housing.

For assessing the performance of the cryotrap, we coupled it to a membrane inlet system (MIS) developed by Short et al. (2001; Fig. 1B). The membrane interface is made of a $13 \mathrm{~mm}$ long PDMS tubing (Helix Medical), which is supported on the inside by a stainless steel spring (Gutekunst) to sustain pressure of up to 20 bar (Bell et al. 2007; Short et al. 2001, 2006a; Wenner et al. 2004). To get stable conditions for the gas transfer through the membrane, the entire MIS is temperature-controlled, and the water is pumped at a constant flow rate along the PDMS tubing.

The cooler and membrane inlet system are mounted in a pressure housing made of aluminium (Fig. 1B). The housing has a length of $290 \mathrm{~mm}$, an outer diameter of $190 \mathrm{~mm}$, and an inner diameter of $180 \mathrm{~mm}$, and is certified to a water depth of $200 \mathrm{~m}$. The housing can be split into two parts of similar length, which are connected by a cap nut made of Polyoxymethylene (POM). This design allows easy access to the cryotrap and MIS for maintenance purposes.

An in situ peristaltic pump (KC Denmark), mounted outside the pressure housing of the cryotrap, is applied to pump water through the membrane inlet system at a constant flow rate of e.g., $3 \mathrm{~mL} \mathrm{~min}^{-1}$. For this purpose, two 1/16-inch Swagelok connectors (SS-100-1-OR) and two stainless steel 1/16-inch capillaries are mounted on the left-hand side of the pressure housing for sample inlet and outlet (Fig. 1B). To transfer the gases through the vacuum line connecting the CT-MIS with the gas analyzer, a $1 / 8$-inch capillary fixed by a $1 / 8$-inch Swagelok connector (SS-200-1-OR) was mounted to one side of the pressure housing. A SubConn connector (eight pin female, BH8F) used for data transfers and acting as a power supply for the heater as well as the cryotrap is mounted at the same side. Therefore, maintenance requires only to unlock the cap nut and to split the housing into two parts (Fig. 1B).

In case of a rupture of the PDMS membrane, the cryotrap will act as a security system. The inflowing water will freeze in the capillary tube connected to the cool finger of the cryotrap, creating an "ice plug" that will block the inflow of liquid water for a few min (Schlüter and Gentz 2008). In addition to the cryotrap, we installed a Pirani pressure sensor (PSG502-S, Inficon, Fig. 1A) to measure the absolute pressure in the vacuum line, and a high vacuum solenoid valve (EVI $005 \mathrm{M}$, Pfeiffer vacuum; Fig. 1A). In case of inflowing water, the fast responding Pirani sensor registers the pressure increase in the vacuum section and triggers the solenoid valve, which uncouples the CT-MIS unit from the gas analyzer.

In our application, we mounted the sensor and solenoid valve into the pressure housing of the gas analyzer, which provides some additional milliseconds of response time (Fig. 1A). Before deployment of the underwater CT-MIS, we flushed the housing with Ar gas. This stabilizes the temperature at the cooling block since precipitation of the air water vapor is avoided. Furthermore, we coated the cooling block with 25 $\mathrm{mm}$ strong insulating material (Armaflex) to further improve the temperature stability.

\section{Assessment}

\section{Specification of the cooling unit}

For assessing the suitability and performance of the cooling unit to trap water vapor at a temperature of $-85^{\circ} \mathrm{C}$, we compared a compact Stirling cooler (Ricor 1/2W Micro, K508) with a novel three layer Peltier cooler (Whatson Marlow, MI4040). From the perspective of underwater deployments, criteria for this assessment were the mechanical robustness, the cool down time, the power consumption required to keep the temperature at $-85^{\circ} \mathrm{C}$, and the waste-heat of the cooler. Because the cryotrap had to be installed within a fully enclosed pressure housing, the waste-heat needed to be transferred from the inside of the housing into the water column.

To compare the two cooler systems, we mounted each of them with its heat sink on a copper block of $60 \times 60 \times 15 \mathrm{~mm}$ in the laboratory and measured the temperature at the cool finger as well as the temperature at the heat sink (Fig. 2). The Stirling cooler reached the target temperature of $-85^{\circ} \mathrm{C}$ within less than $60 \mathrm{~min}$ (Fig. 2A). This temperature as well as the temperature of the heat sink (about $+40^{\circ} \mathrm{C}$ ) remained stable for more than 1300 min.

In comparison, the Peltier element reached a temperature of $-55.3^{\circ} \mathrm{C}$ after about $2 \mathrm{~min}$. The temperature of the heat sink increased continuously and reached a temperature of more than $80^{\circ} \mathrm{C}$ after $13 \mathrm{~min}$ (Fig. 2B). Since the cold side and the heat sink of the Peltier element are less than $14.1 \mathrm{~mm}$ apart, the area of the copper block had to be increased considerably to transfer the heat into the environment. To keep the temperature constant at the heat sink as well as the cold site of the Peltier element, we applied a water-cooled heat sink and installed the Peltier element in an Ar gas environment. This improved the performance of the Peltier element considerably. Nevertheless, for underwater applications, this would require an additional pump to circulate water from the outside 

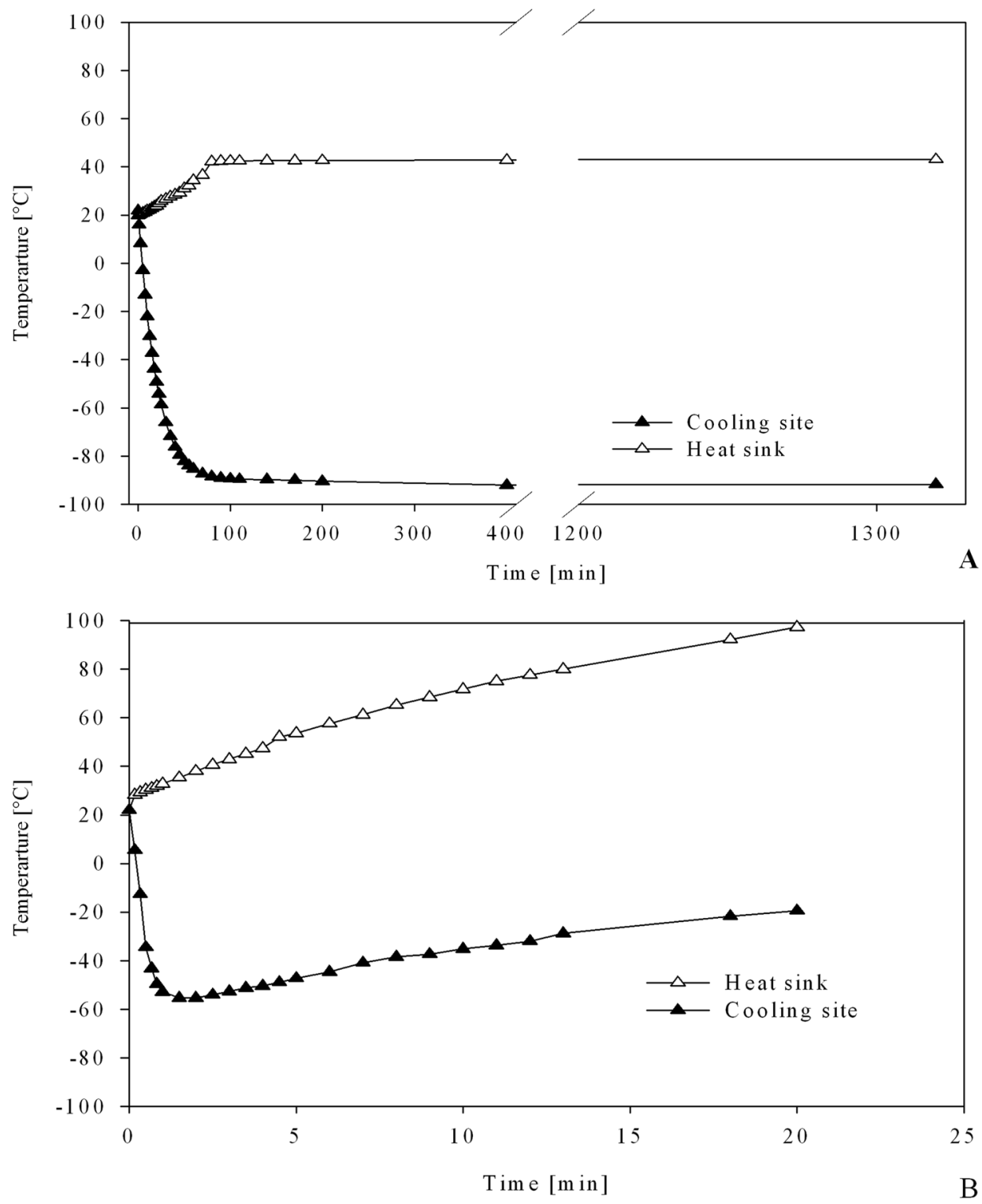

Fig. 2. Comparison of the temperature measured versus time at the cooling site and heat sink of the Stirling cooler (A) and the Peltier element (B).

into the pressure housing through the heat sink and back into the water column. This pump would entail additional energy requirements and result in considerable modifications of the pressure housing to avoid any risks of leaks.

To reach and keep the target temperature, the Peltier element required more than $80 \mathrm{~W}$ at $6.8 \mathrm{~V}$. In contrast, the Stirling cooler required $6 \mathrm{~W}$ at $24 \mathrm{~V}$ to keep the cool finger at a temperature of $-85^{\circ} \mathrm{C}$ throughout. Based on these results, we decided to use the Stirling cooler within the CT-MIS.

Temporal development of the water vapor content within the vacuum line

We investigated the performance of the CT-MIS mounted in the pressure housing with respect to the reduction of the water vapor content in the vacuum section, the improvement of the signal detected by the gas analyzer, and the service life time. For this assessment, we connected the CT-MIS to the InSpectr200-200.

To investigate the development of the water vapor content versus time (Fig. 3), $\mathrm{CH}_{4}$-free water was prepared by purging synthetic air through distillated water. The water vapor was measured by the mass spectrometer (intensities are displayed as ion current in ampere) at the $\mathrm{m} / \mathrm{z} 18$ with the highest relative abundance (also detectable at m/z 17 and m/z 16). Also, the absolute pressure (Torr) measured by the Pirani sensor and the temperature of the cryotrap are shown in Fig. 3.

Starting at an ambient temperature of $22^{\circ} \mathrm{C}$, the water vapor peak at $\mathrm{m} / \mathrm{z} 18$ having reached an intensity of $\sim 1.8 \times 10^{-7}$ 


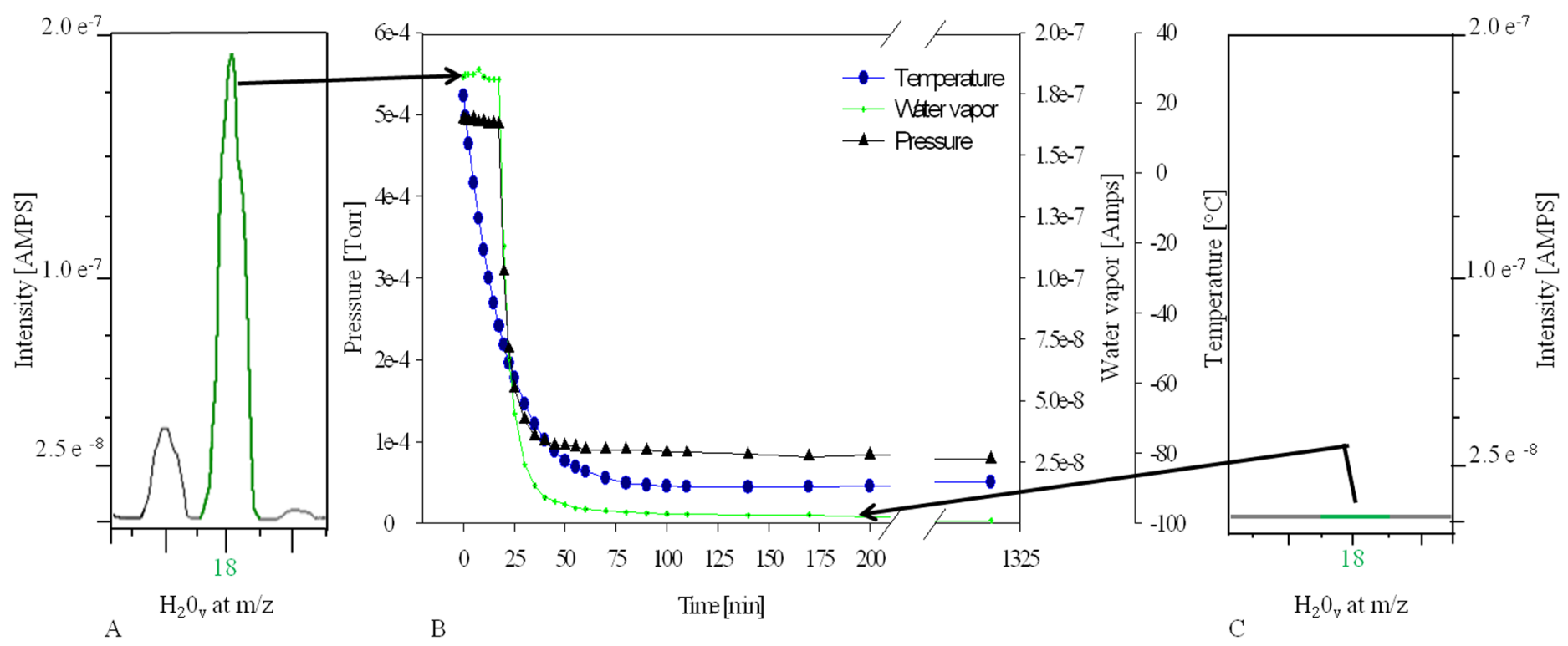

Fig. 3. (A) Water vapor peak intensity at $\mathrm{m} / \mathrm{z} 18$ before the cooling. (B) Reduction of the internal pressure, water vapor intensities, and temperature versus after the Stirling cooler was switched on. (C) Water vapor peak intensity at $\mathrm{m} / \mathrm{z} 18$ after a cooling time of $240 \mathrm{~min}$. Comparing (A) and (C) results a signal reduction at $\mathrm{m} / \mathrm{z} 18$ of $96 \%$.

Ampere (AMPS, Fig. 3A). After $26 \mathrm{~min}$, the cryotrap reached a temperature of $-60^{\circ} \mathrm{C}$, and a significant reduction of $\mathrm{H}_{2} \mathrm{O}_{\mathrm{v}}$ was observed (Fig. $3 \mathrm{~B}$ ), which also caused a significant reduction of the absolute pressure in the vacuum section from $4.95 \times 10^{-4}$ Torr to $1.65 \times 10^{-4}$ Torr. After $1 \mathrm{~h}$, the target temperature of $-85^{\circ} \mathrm{C}$ was reached, the pressure is reduced to $0.902 \times 10^{-4}$ Torr, and about $96 \%$ of initial water vapor was trapped by the cryotrap. After $140 \mathrm{~min}$, the absolute pressure was reduced by factor six to $0.842 \times 10^{-4}$ Torr (Fig. 3B). At this point, no significant peak was detected at $\mathrm{m} / \mathrm{z} 18$ (Fig. 3C), which means that most of the $\mathrm{H}_{2} \mathrm{O}_{\mathrm{v}}(98 \%)$ was trapped in the cryotrap. Due to this reduced pressure at the ion source, a higher electron emission current, which would increase the ionization efficiency, and a higher voltage at the electron multiplier could be applied, which would improve the detection limit of all gases.

Compared with most cryotraps applied in laboratories, where, e.g., U-shaped traps are used, and the cooling section can be easily shifted, only a small section of the vacuum line was cooled down to trap $\mathrm{H}_{2} \mathrm{O}_{\mathrm{v}}$ in our underwater applications. Therefore, we investigated the impact of the deposition and formation of ice coatings within the capillary. For this purpose, we also used methane-free water and measured the intensity at $\mathrm{m} / \mathrm{z}$ ratios $40,32,28,18$, and 15 representatives for $\mathrm{Ar}, \mathrm{O}_{2}, \mathrm{~N}_{2}, \mathrm{H}_{2} \mathrm{O}_{\mathrm{v}}$, and $\mathrm{CH}_{4}$ over several hours (Fig. 4B). Here, special attention was paid to the change of background signal at $\mathrm{m} / \mathrm{z} 15$ (methane) and the signal stability of argon, oxygen, and nitrogen. At the beginning of the cooling, interferences overlapped the background signal of methane at m/z 15 and a high signal/noise ratio was observed (Fig. 4A). The interferences appeared due to a combination of the low mass "tail" of the very large m/z 16 peak arising from ionization of $\mathrm{H}_{2} \mathrm{O}_{\mathrm{v}}$ as well as from the ionization of $\mathrm{O}_{2}$ (producing single charged atomic oxygen ${ }^{16} \mathrm{O}$ ). Trapping the water vapor (Fig. 4B) downgraded this interference, and the signal/noise ratio at $\mathrm{m} / \mathrm{z} 15$ is improved (Fig. 4C). This effect, combined with a higher electron emission current, lowered the detection limit of the trace gas $\mathrm{CH}_{4}$ from values of more than $100 \mathrm{nmol} \mathrm{L}^{-1}$ to 16nmol L-1 (Schlüter and Gentz 2008).

Considering the signal intensities observed for nitrogen, oxygen, and argon over time suggested a linear signal reduction of $3.3 \% \mathrm{~h}^{-1}$ for $10 \mathrm{~h}$ (Fig.4B). Due to the contribution of $\mathrm{O}_{2}$ at $\mathrm{m} / \mathrm{z} 15$, the same signal reduction was measured for methane. We assumed that this signal reduction was mainly due to the decreasing inner diameter of the capillary caused by the deposition of $\mathrm{H}_{2} \mathrm{O}_{\mathrm{v}}$. This effect could be quantified and conveyed to the measured mass spectrometer intensities.

For underwater applications, the system has to be started about 90 min before to ensure the drop down of $\mathrm{H}_{2} \mathrm{O}_{\mathrm{v}}$ Based on our laboratory measurements, as well as experience gained during our field assessments, the CT-MIS can be operated in situ for more than $10 \mathrm{~h}$. After the maximum operating time, ice coating in the capillary of the cryotrap has to been removed by switching off the cooler, which causes the cool block to warm up and the ice coat to sublimate. The originating water vapor is removed by the turbo pump and roughing pump of the mass spectrometer. The entire maintenance procedure takes about $1 \mathrm{~h}$.

\section{Application}

For field applications, we coupled the CT-MIS to the underwater mass spectrometer Inspectr 200-200. The gas analysis 


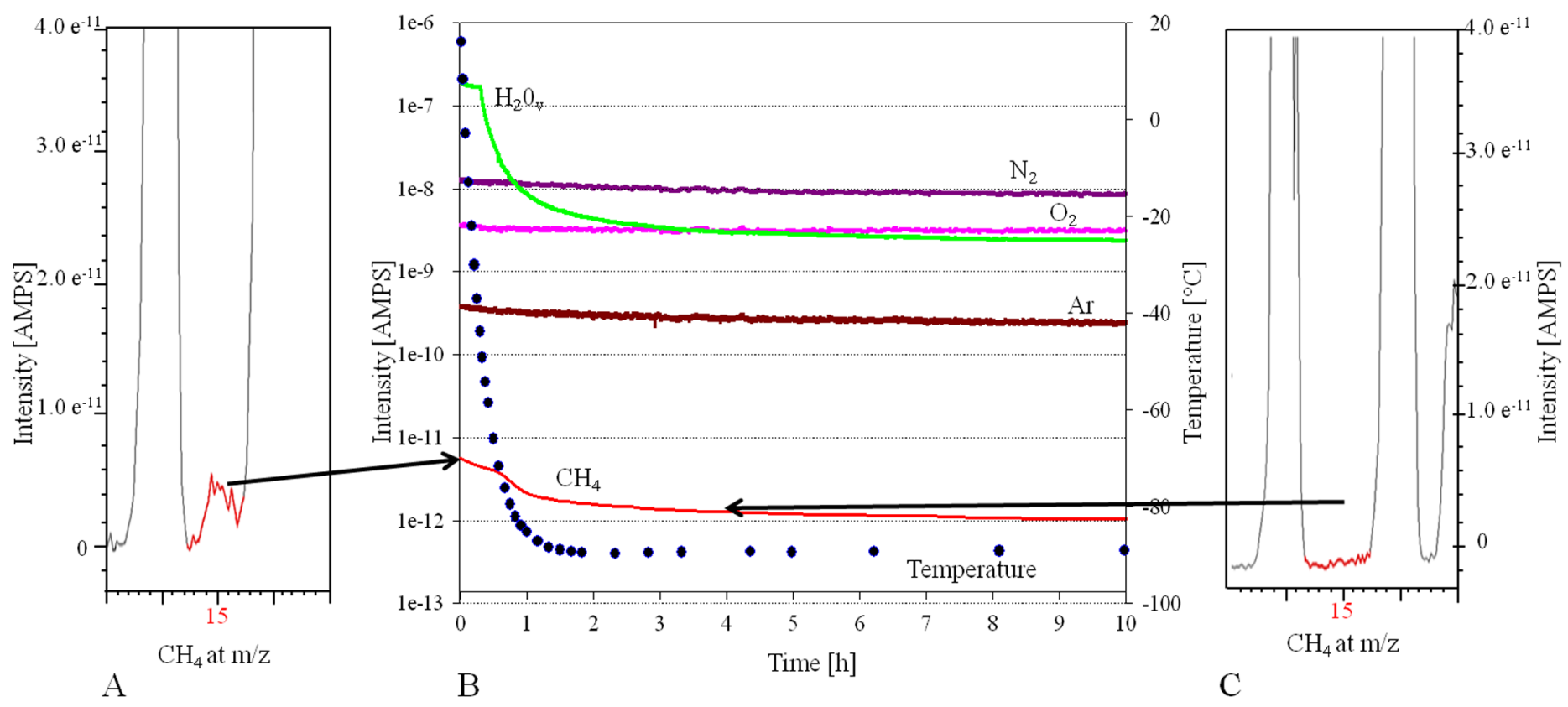

Fig. 4. For the assessment of the peak stability of selected gases during the cooling by the CT-MIS, methane-free water was used. (A) Methane background signal at $\mathrm{m} / \mathrm{z} 15$ before cooling. (B) lon current intensities versus time during the cooling process measured for methane-free water at $\mathrm{m} / \mathrm{z}$ rations of $28\left(\mathrm{~N}_{2}\right), 32\left(\mathrm{O}_{2}\right), 40(\mathrm{Ar}), 18\left(\mathrm{H}_{2} \mathrm{O}_{\mathrm{v}}\right)$ and $15\left(\mathrm{CH}_{4}\right)$. (C) Methane background signal at m/z 15 after 240 min of cooling.

unit, as well as a benthic chamber system, an underwater peristaltic pump and the power supply (two SeaBatteries, SB24-40, $24 \mathrm{~V}$, and $40 \mathrm{Ah}$ ) were mounted to a deployment frame (Fig. 5A). We applied this system for investigating the distribution of $\mathrm{CH}_{4}$ in the water column around gas seeps in the North Sea. To detect the release of gases from sediments in Gdansk Bay (Baltic Sea), a smaller frame consisting of the CTMIS coupled to the mass spectrometer, the underwater pump, and the power supply (one SeaBatteries, SB24-40, 24 V, 40 Ah) was used. The benthic chamber was placed manually into the sediment. During these in situ measurements, we monitored the water vapor content, the intensity of the gases $\mathrm{CH}_{4}, \mathrm{~N}_{2}, \mathrm{O}_{2}$, $\mathrm{Ar}$, and $\mathrm{CO}_{2}$, the total energy consumption of the system, as well as the robustness of the CT-MIS.

In situ investigation of $\mathrm{CH}_{4}$ in the water column around gas seeps (North Sea)

In the North Sea, ebullitions of gas bubbles from the seafloor have been observed along fracture zones where thermogenic gases or natural $\mathrm{CO}_{2}$ are released, in regions where biogenic $\mathrm{CH}_{4}$ is produced in surface sediments, as well as at gas releases of former wellheads (Clayton et al. 1997; Rehder et al. 1998; Schroot et al. 2005; McGinnis et al. 2011; Niemann et al. 2005; Von Deimling et al. 2011). During RV Heincke cruise HE337 in September/October 2010, we investigated hydrocarbon seeps associated with pockmark structures situated at a fracture zone in the Dutch sector of the North Sea (Schroot et al. 2005; Schroot and Schuttenhelm 2003a, 2003b).
Before deployment, the seafloor around the pockmark area was mapped with a Kongsberg SIS multibeam system, and the Simrad EK 60 echo sounder was applied for the detection of gas flares in the water column (Fig. 5B). The area of our detailed investigation had a size of $500 \mathrm{~m} \times 400 \mathrm{~m}$ (Fig. 5B). Within this area, the investigated pockmark, where an active release of gas bubbles was observed, had a diameter of less than $5 \mathrm{~m}$.

For mapping the concentration field of dissolved $\mathrm{CH}_{4}$, the CT-MIS coupled to the InSpectr200-200 was deployed in water depths of $10 \mathrm{~m}, 14 \mathrm{~m}, 24 \mathrm{~m}$, and $34 \mathrm{~m}$. When the system had reached the respective depth, the research vessel moved slowly around and across the site of gas seepage whereas gas concentrations were measured continuously every $1.8 \mathrm{~s}$. One hour of measuring time was estimated for each water depth. The data were integrated into the Geo-Information-System ArcGIS 10 (ESRI), and contour plots were computed by Kriging.

The in situ analysis provided very detailed information about the concentration field of $\mathrm{CH}_{4}$ around gas flares (Fig. 5). Within the rather small sampling area of $280 \mathrm{~m} \times 280 \mathrm{~m}$ (78400 $\mathrm{m}^{2}$, Fig. 5C), steep concentration gradients of more than $1200 \mathrm{nmol} \mathrm{L}^{-1}$ in less than $20 \mathrm{~m}$ were detected, and the methane concentrations varied from values of less than 16 nmol $\mathrm{L}^{-1}$ about $60 \mathrm{~m}$ adjacent to the pockmark to high concentrations of $1450 \mathrm{nmol} \mathrm{L}^{-1}$ within the gas flare.

In situ measurement of gas fluxes across the sedimentwater interface (Baltic Sea)

Several biogeochemical investigations used the flux of $\mathrm{O}_{2}$ or nutrients through the sediment water interface to study the 


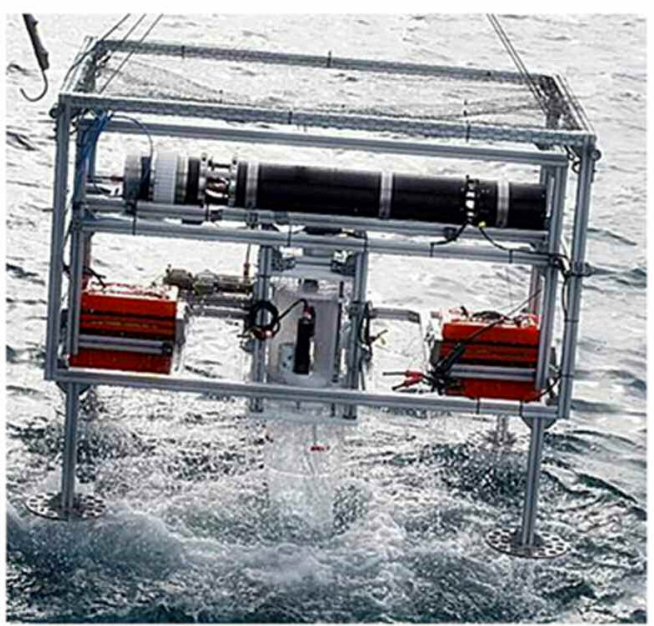

A
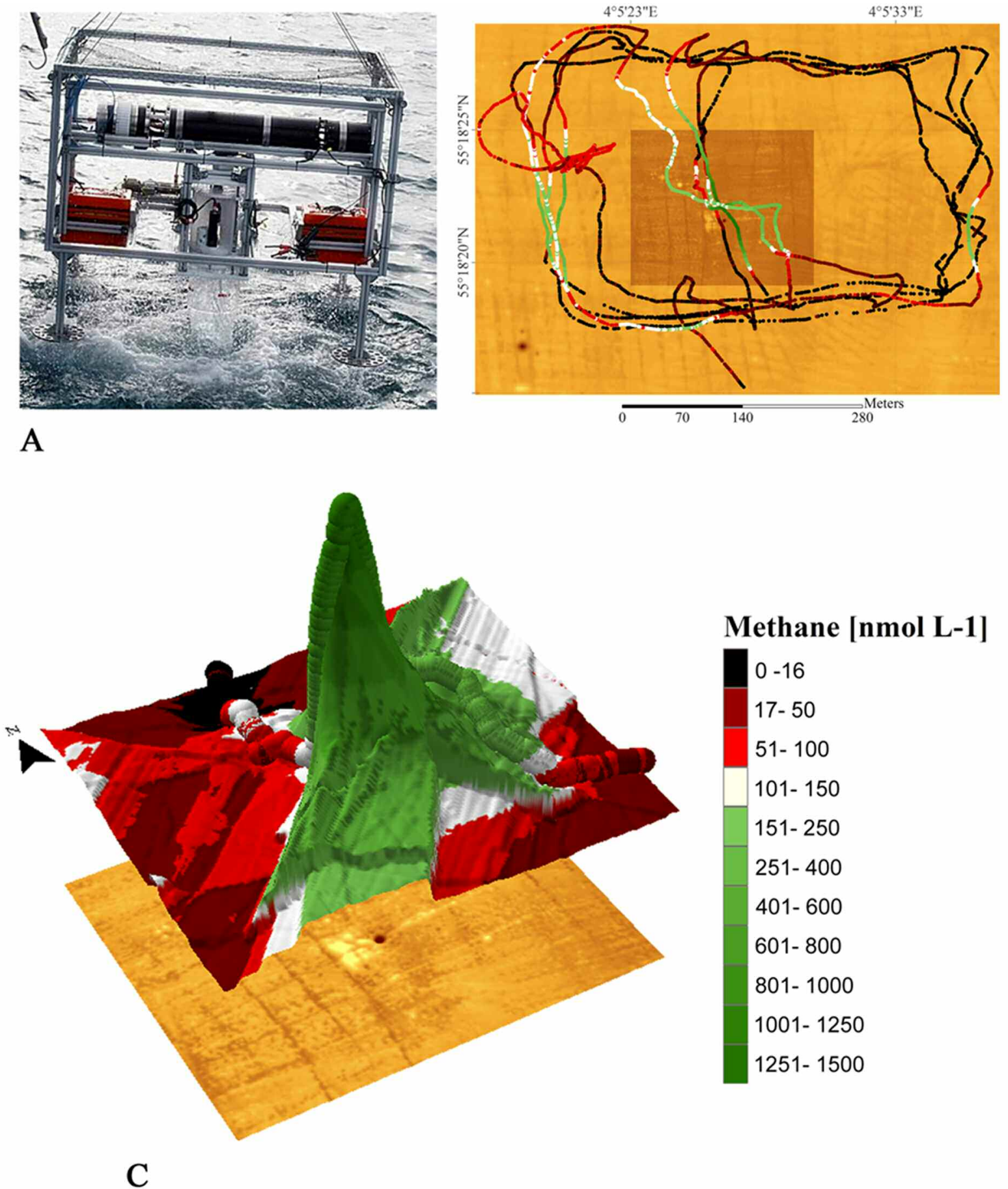

Fig. 5. In situ methane measurements around a pockmark in the North Sea. (A) Deployment frame where the CT-MIS is coupled to the underwater mass spectrometer. (B) High resolution bathymetric map derived by a multibeam survey. The pockmark, where methane is released from the seafloor, has a diameter of less than $5 \mathrm{~m}$. (C) Methane concentrations measured at $24 \mathrm{~m}$ water depth. Close to the pockmark, step gradients in the $\mathrm{CH}_{4}$ concentrations of more than $1430 \mathrm{nmol} \mathrm{L}^{-1}$ were observed.

remineralization of organic matter or to quantify the rain rate of organic matter reaching the seafloor. The latter is investigated through the in situ measurement of $\mathrm{O}_{2}$ by either applying benthic chamber systems or $\mathrm{O}_{2}$ microprofiler, for example Glud et al. (1994) and Sauter et al. (2001).
Beside $\mathrm{O}_{2}$ fluxes, only a rather limited number of investigations considered the flux of gases like $\mathrm{CO}_{2}, \mathrm{CH}_{4}, \mathrm{DMS}$, or $\mathrm{N}_{2}$ through the sediment water interface (Felden et al. 2010; Lichtschlag et al. 2010; Niemann et al. 2005). For these purposes, benthic chamber systems are applied, and water samples 
(typically 12 samples with a volume of $50 \mathrm{~mL}$ each) are collected within predefined time intervals by using a syringe sampler, for example. Fluxes are calculated based on the change of gas concentrations within the chamber over time. The limited number of samples and the sample volume restricts the detailed investigation of changes in concentration versus time as well as the number of gases, which can be analyzed.

Coupling the underwater gas analyzer system to a benthic chamber allows the continuous measurement of gas concentrations for gases like $\mathrm{O}_{2}, \mathrm{~N}_{2}$, DMS, and $\mathrm{CH}_{4}$ over time, and thus allows the study of gas fluxes in coastal areas. In our application, the deployed cylindrical benthic chamber had an inner diameter of $290 \mathrm{~mm}$ and a height of $170 \mathrm{~mm}$. It was manually placed into the sediment at a depth of $20 \mathrm{~mm}$, and a stirrer prevented stratification inside the chamber. The entrapped bottom water was recirculated through the CT-MIS and back into the benthic chamber using an underwater peristaltic pump. During the measurements by the membrane inlet, less than $1 \%$ of the gases were extracted from the sampling water in the benthic chamber and the gas concentrations of $\mathrm{Ar}, \mathrm{O}_{2}, \mathrm{CH}_{4}$, and $\mathrm{CO}_{2}$ were measured every $1.8 \mathrm{~s}$ for more than $5.5 \mathrm{~h}$.

With this application, we investigate the gas fluxes across the sediment-water interface in the shallow water region of Gdansk Bay (Baltic Sea). In this area, advective transport of methane induced by submarine groundwater discharge is the main driver for high methane concentration in the bottom water $\left(920 \mu \mathrm{mol} \mathrm{L} \mathrm{L}^{-1}\right)$. Benthic chamber measurements over a period of $5 \mathrm{~h}$ discovered that $\mathrm{CH}_{4}$ and $\mathrm{CO}_{2}$ were enriched in the chamber, while the $\mathrm{O}_{2}$ concentration decreased (Fig. 6). In this example, the methane concentration in the benthic chamber increased to about $238.8 \mu \mathrm{mol} \mathrm{L}^{-1}$ within $60 \mathrm{~min}$ and the calculated flux of methane amounted to $97400 \pm 40 \mu \mathrm{mol}$ $\mathrm{m}^{2} \mathrm{~d}^{-1}$ which is comparable with other regions with advective transport of methane occurrences (Lichtschlag et al. 2010; Boetius and Suess 2004).

Another type of benthic flux studies focuses on the diffusive methane fluxes from coastal sediments. In regions unaffected by advection, we can generally expect rather low methane fluxes and concentrations in the bottom water (Reeburgh and Heggie 1977). This is the case for most Baltic Sea regions (Gentz unpubl. data; Piker et al. 1998). In Himmerfjärden, a low-salinity estuarine system in the central Baltic Sea, online measurements by the CT-MIS coupled to the mass spectrometer show a methane flux of $331.5 \mu \mathrm{mol} \mathrm{m} \mathrm{m}^{2} \mathrm{~d}^{-1}$. Without the CT-MIS, the enrichment of the methane concentration of $0.081 \mu \mathrm{mol} \mathrm{L}{ }^{-1}$ within $60 \mathrm{~min}$ in the sampled water would be below the detection limit $\left(>100 \mathrm{nmol} \mathrm{L}^{-1}\right)$ of the gas analyzer. By using the CT-MIS, the enrichment of the methane concentration in the sampled water $\left(0.081 \mu \mathrm{mol} \mathrm{L}^{-1}\right.$ within 60 $\mathrm{min}$ ) is five times higher than the lowered detection limit (16 nmol $\mathrm{L}^{-1}$ ), which provides a statistical ensured flux measurement of methane also in regions were very low methane fluxes are expected.

\section{Discussion}

Membrane inlet systems have been widely used for the phase separation of gases from seawater or freshwater samples before gas analyses by mass spectrometers, IR sensors, or solid state gas detectors. Even if various membrane materials with different characteristics in terms of water vapor permeation are applied, a significant amount of $\mathrm{H}_{2} \mathrm{O}_{\mathrm{v}}$ is introduced into the analyzer unit. This $\mathrm{H}_{2} \mathrm{O}_{v}$ could downgrade the detection limits, induce water condensation within optical sections, or generate a drift of the signals. With respect to these issues, we consider the cryotrap membrane inlet system described and

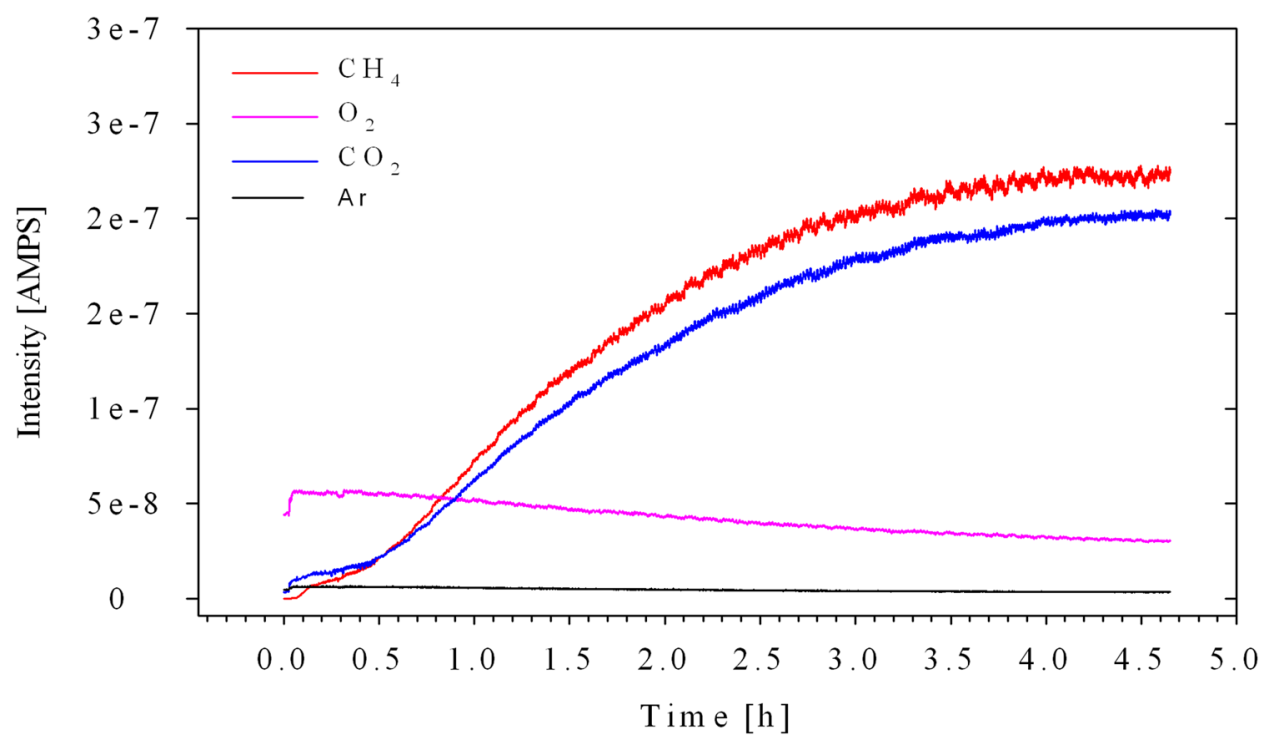

Fig. 6. In situ benthic flux measurements of methane, carbon dioxide, oxygen, and argon by the CTMIS coupled to the InSpectr200-200 in the Gdansk Bay (Baltic Sea). 
tested here to be an improvement with regard to the analysis of major- and trace gases.

For the online and onsite analysis of methane, applying the CT-MIS lowers the detection limit of the mass spectrometer significantly, which allows an improved computation of mass budgets and supports the localization of point sources like natural methane seeps or gas flares as well as anthropogenic gas leakages considerably. This can be evidenced by measurements obtained for a water depth of $24 \mathrm{~m}$ around a gas flare in the North Sea (Fig. 5C). Considering the entire survey area of $78401 \mathrm{~m}^{2}, \mathrm{CH}_{4}$ concentrations of less than $16 \mathrm{nmol} \mathrm{L}^{-1}$ were observed for an area of $2840 \mathrm{~m}^{2}$ (3.6\%, black-coded region in Fig. 5C). For an area of $37827 \mathrm{~m}^{2}$ (48.3\%, red-coded region in Fig. 5C), $\mathrm{CH}_{4}$ concentrations were established between 16 and $100 \mathrm{nmol} \mathrm{L}^{-1}$, whereas concentrations of more than $100 \mathrm{nmol} \mathrm{\textrm {L } ^ { - 1 }}$ were detected for an area of $37734 \mathrm{~m}^{2}$ (48.1\%, white- and green-coded region in Fig. 5C). Without applying the CT-MIS, $\mathrm{CH}_{4}$ would be detected only within an area of $37734 \mathrm{~m}^{2}$. Consequently, more survey time would be required to localize such point sources of methane release.

The present possibility to measure lower concentrations of down to $16 \mathrm{nmol} \mathrm{L}^{-1}$, which are often observed in various aquatic environments, helps to guide the research vessel (in case of using a towed system as shown in Fig. 5A) or a Remotely Operated Vehicle (ROV) toward the direction of a gas discharge site. Furthermore, a considerable underestimation of mass budgets could be avoided if data from the extended concentration range (16 to $100 \mathrm{nmol} \mathrm{L}^{-1}$ ) would be included to the calculations.

From an analytical point of view, the results demonstrate the benefits of the CT-MIS coupled to a gas analyzer. Considering the technical perspective, issues mentioned in the introduction have been tested in the field (e.g., robustness, energy consumption, and service life time) as well as in the laboratory (e.g., temperature settings) and successfully meet the requirements for using the CT-MIS in harsh environments, especially aboard research vessels, as well as underwater applications. Therefore, the CT-MIS could be simply adapted to other membrane inlet gas analyzers (Boulart et al. 2010; Johnson et al. 2000) where the reduction of water vapor would improve the performance, such as detection limits and lifetime of these analyzers, significantly.

\section{References}

Bell, R. J., R. T. Short, F. H. W. Van Amerom, and R. H. Byrne. 2007. Calibration of an in situ membrane inlet mass spectrometer for measurements of dissolved gases and volatile organics in seawater. Environ. Sci. Technol. 41:8123-8128 [doi:10.1021/es070905d].

— - , and R. H. Byrne. 2011. In situ determination of total dissolved inorganic carbon by underwater membrane introduction mass spectrometry. Limnol. Oceanogr. Methods 9:164-175 [doi:10.4319/lom.2011.9.164].

Boetius, A., and E. Suess. 2004. Hydrate Ridge: a natural laboratory for the study of microbial life fueled by methane from near-surface gas hydrates. Chem. Geol. 205:291-310 [doi:10.1016/j.chemgeo.2003.12.034].

Boulart, C., M. C. Mowlem, D. P. Connelly, J. P. Dutasta, and C. R. German. 2008. A novel, low-cost, high performance dissolved methane sensor for aqueous environments. Opt. Express 16:12607-12617 [doi:10.1364/OE.16.012607].

, D. P. Connelly, and M. C. Mowlem. 2010. Sensors and technologies for in situ dissolved methane measurements and their evaluation using Technology Readiness Levels. Trends Anal. Chem. 29:186-195 [doi:10.1016/j.trac.2009. 12.001].

Butler, J. H., and J. W. Elkins. 1991. An automated technique for the measurement of dissolved N2o in natural waters. Mar. Chem. 34:47-61 [doi:10.1016/0304-4203(91)90013-M]. Camilli, R., and H. Hemond. 2002. NEREUS engineering concept for an underwater mass spectrometer. Trends Anal. Chem. 23:307-313 [doi:10.1016/S0165-9936(04)00408-X].

—, B. Bingham, C. M. Reddy, R. K. Nelson, and A. N. Duryea. 2009. Method for rapid localization of seafloor petroleum contamination using concurrent mass spectrometry and acoustic positioning. Mar. Pollut. Bull. 58:15051513 [doi:10.1016/j.marpolbul.2009.05.016].

Clayton, C. J., S. J. Hay, S. A. Baylis, and B. Dipper. 1997. Alteration of natural gas during leakage from a North Sea salt diapir field. Mar. Geol. 137:69-80 [doi:10.1016/S00253227(96)00080-1].

Damm, E., R. P. Kiene, J. Schwarz, E. Falck, and G. Dieckmann. 2008. Methane cycling in Arctic shelf water and its relationship with phytoplankton biomass and DMSP. Mar. Chem. 109:45-59 [doi:10.1016/j.marchem.2007.12.003].

Desmarais, D. J. 1978. Variable-temperature cryogenic trap for separation of gas-mixtures. Anal. Chem. 50:1405-1406 [doi:10.1021/ac50031a056].

Emerson, S., C. Stump, B. Johnson, and D. M. Karl. 2002. In situ determination of oxygen and nitrogen dynamics in the upper ocean. Deep-Sea Res I 49:941-952 [doi:10.1016/ S0967-0637(02)00004-3].

Felden, J., F. Wenzhöfer, T. Feseker, and A. Boetius. 2010. Transport and consumption of oxygen and methane in different habitats of the Hakon Mosby Mud Volcano (HMMV). Limnol. Oceanogr. 55:2366-2380 [doi:10.4319/lo.2010.55. 6.2366].

Glud, R. N., J. K. Gundersen, N. P. Revsbech, and B. B. Jørgensen. 1994. Effects on the benthic diffusive boundary layer imposed by microelectrodes. Limnol. Oceanogr. 39:462-467.

Gueguen, C., and P. D. Tortell. 2008. High-resolution measurement of Southern Ocean $\mathrm{CO}_{2}$ and O-2/Ar by membrane inlet mass spectrometry. Mar. Chem. 108:184-194 [doi:10.1016/j.marchem.2007.11.007].

Hovland, M., and A. G. Judd. 1988. Seabed pockmarks and seepages. Graham and Trotman.

Johnson, K. M., A. Körtzinger, L. Mintrop, J. C. Duinker, and D. W. R. Wallace. 1999. Coulometric total carbon dioxide 
analysis for marine studies: measurement and internal consistency of underway TCO2 concentrations. Mar. Chem. 67:123-144 [doi:10.1016/S0304-4203(99)00055-9].

Johnson, R. C., R. G. Cooks, T. M. Allen, M. E. Cisper, and P. H. Hemberger. 2000. Membrane introduction mass spectrometry: Trends and applications. Mass Spectrom. Rev. 19:1-37 [doi:10.1002/(SICI)1098-2787(2000)19:1<1::AIDMAS1>3.0.CO;2-Y].

Kampbell, D. H., J. T. Wilson, and S. A. Vandegrift. 1989. Dissolved-oxygen and methane in water by a GC headspace equilibration technique. Int. J. Environ. Anal. Chem. 36:249-257 [doi:10.1080/03067318908026878].

Kolb, B., G. Zwick, and M. Auer. 1996. A water trap for static cryo-headspace gas chromatography. J. High Resolut. Chromatogr. 19:37-42 [doi:10.1002/jhrc.1240190107].

Leifer, I., and J. Boles. 2005a. Measurement of marine hydrocarbon seep flow through fractured rock and unconsolidated sediment. Mar. Petrol. Geol. 22:551-568 [doi:10.1016/j.marpetgeo.2004.10.026].

- and 2005b. Turbine tent measurements of marine hydrocarbon seeps on subhourly timescales. J. Geophys. Res. Oceans 110 [doi:10.1029/2003JC002207].

Lichtschlag, A., and others. 2010. Methane and sulfide fluxes in permanent anoxia: In situ studies at the Dvurechenskii mud volcano (Sorokin Trough, Black Sea). Geochim. Cosmochim. Acta 74:5002-5018 [doi:10.1016/j.gca.2010.05.031].

Lloyd, D., K. Thomas, D. Price, B. Oneil, K. Oliver, and T. N. Williams. 1996. A membrane-inlet mass spectrometer miniprobe for the direct simultaneous measurement of multiple gas species with spatial resolution of $1 \mathrm{~mm}$. J. Microbiol. Methods 25:145-151 [doi:10.1016/0167-7012 (96)00011-5].

McCarthy, M. J., and W. S. Gardner. 2003. An application of membrane inlet mass spectrometry to measure denitrification in a recirculating mariculture system. Aquaculture 218:341-355 [doi:10.1016/S0044-8486(02)00581-1].

McGinnis, D. F., J. Greinert, Y. Artemov, S. E. Beaubien, and A. Wuest. 2006. Fate of rising methane bubbles in stratified waters: How much methane reaches the atmosphere? J. Geophys. Res. Oceans 111:C09007 [doi:10.1029/2005JC003183].

- and others. 2011. Discovery of a natural $\mathrm{CO}_{2}$ seep in the German North Sea: Implications for shallow dissolved gas and seep detection. J. Geophys. Res. 116:C03013 [doi:10.1029/2010JC006557].

McMurtry, G. M., J. C. Wiltshire, and A. Bossuyt. 2005. A deep ocean mass spectrometer to monitor hydrocarbon seeps and pipelines. In ASME 2005 24th International Conference on Offshore Mechanics and Arctic Engineering, Halkidiki, Greece. [doi:10.1115/OMAE2005-67146].

Melin, T., and R. Tautenbach. 2006. Membranverfahren, Grundlagen der Modul- und Anlagenauslegung. SpringerVerlag.

Mendes, M. A., R. S. Pimpim, T. Kotiaho, J. S. Barone, and M. N. Eberlin. 1996a. The construction of a membrane probe and its application towards the analysis of volatile organic compounds in water via the MIMS and MIMS/MS techniques. Quim Nova 19:480-485.

—, R. S. Pimpim, T. Kotiaho, and M. N. Eberlin. 1996b. A cryotrap membrane introduction mass spectrometry system for analysis of volatile organic compounds in water at the low parts-per-trillion level. Anal. Chem. 68:3502-3506 [doi:10.1021/ac9604346].

Milkov, A. V. 2000. Worldwide distribution of submarine mud volcanoes and associated gas hydrates. Mar. Geol. 167:2942 [doi:10.1016/S0025-3227(00)00022-0].

Niemann, H., and others. 2005. Methane emission and consumption at a North Sea gas seep (Tommeliten area). Biogeosciences 2:335-351 [doi:10.5194/bg-2-335-2005].

Peters, L. I., and D. Yakir. 2010. A rapid method for the sampling of atmospheric water vapour for isotopic analysis. Rapid Commun. Mass Spectrom. 24:103-108 [doi:10.1002/ rcm.4359].

Piker, L., R. Schmaljohann, and J. F. Imhoff. 1998. Dissimilatory sulfate reduction and methane production in Gotland Deep sediments (Baltic Sea) during a transition period from oxic to anoxic bottom water (1993-1996). Aquat. Microb. Ecol. 14:183-193 [doi:10.3354/ame014183].

Prien, R. D. 2007. The future of chemical in situ sensors. Mar. Chem. 107:422-432 [doi:10.1016/j.marchem.2007.01.014].

Reeburgh, W. S., and D. T. Heggie. 1977. Microbial methane consumption reactions and their effect on methane distributions in freshwater and marine environments. Limnol. Oceanogr.22:1-9 [doi:10.4319/lo.1977.22.1.0001].

Rehder, G., R. S. Keir, E. Suess, and T. Pohlmann. 1998. The multiple sources and patterns of methane in North Sea waters. Aquat. Geochem. 4:403-427 [doi:10.1023/A:10096 44600833].

Sahling, H., and others. 2008. Pockmarks in the Northern Congo Fan area, SW Africa: Complex seafloor features shaped by fluid flow. Mar. Geol. 249:206-225 [doi:10.1016/j.margeo.2007.11.010].

Saltzman, E. S., W. J. De Bruyn, M. J. Lawler, C. A. Marandino, and C. A. McCormick. 2009. A chemical ionization mass spectrometer for continuous underway shipboard analysis of dimethylsulfide in near-surface seawater. Ocean Sci. 5:537-546 [doi:10.5194/os-5-537-2009].

Sauter, E. J., M. Schlüter, and E. Suess. 2001. Organic carbon flux and remineralization in surfacsaltzmane sediments from the northern North Atlantic derived from pore-water oxygen microprofiles. Deep Sea Res. I 48:529-553 [doi:10.1016/S0967-0637(00)00061-3].

—, and others. 2006. Methane discharge from a deep-sea submarine mud volcano into the upper water column by gas hydrate-coated methane bubbles. Earth Planet Sci. Lett. 243:354-365 [doi:10.1016/j.epsl.2006.01.041].

Schlüter, M., P. Linke, and E. Suess. 1998. Geochemistry of a sealed deep-sea borehole on the Cascadia Margin. Mar. Geol. 148:9-20 [doi:10.1016/S0025-3227(98)00016-4]. 
and T. Gentz. 2008. Application of membrane inlet mass spectrometry for online and in situ analysis of methane in aquatic environments. J. Am. Soc. Mass Spectrom. 19:1395-1402 [doi:10.1016/j.jasms.2008.07.021].

Schroot, B. M., and R. T. E. Schüttenhelm. 2003a. Expressions of shallow gas in the Netherlands North Sea. Neth. J. Geosci. 82:91-105.

and 2003b. Shallow gas and gas seepage: expressions on seismic and other acoustic data from the Netherlands North Sea. J Geochem Explor 78-9:305-309.

, G. T. Klaver, and R. T. E. Schüttenhelm. 2005. Surface and subsurface expressions of gas seepage to the seabedexamples from the Southern North Sea. Mar. Petrol. Geol. 22:499-515 [doi:10.1016/j.marpetgeo.2004.08.007].

Short, R. T., and others. 2001. Underwater mass spectrometers for in situ chemical analysis of the hydrosphere. J. Am. Soc. Mass Spectrom. 12:676-682 [doi:10.1016/S1044-0305(01) 00246-X].

, D. P. Fries, S. K. Toler, C. E. Lembke, and R. H. Byrne. 2006a. Development of an underwater mass spectrometry system for in-situ chemical analysis. Meas. Sci. Technol. 10:1195-1201 [doi:10.1088/0957-0233/10/12/311].

, S. K. Toler, G. P. G. Kibelka, D. T. R. Roa, R. J. Bell, and R. H. Byrne. 2006b. Detection and quantification of chemical plumes using a portable underwater membrane introduction mass spectrometer. Trend Anal. Chem. 25:637-646 [doi:10.1016/j.trac.2006.05.002].

Simmonds, P. G. 1984. Analysis of trace halocarbons in natural-waters by simplified purge and cryotrap method. J. Chromatogr. 289:117-127 [doi:10.1016/S0021-9673(00) 95081-7].

Suess, E., and others. 1999. Gas hydrate destabilization: enhanced dewatering, benthic material turnover and large methane plumes at the Cascadia convergent margin. Earth Planet Sci. Lett. 170:1-15 [doi:10.1016/S0012-821X(99) 00092-8].

Tortell, P. D. 2005. Dissolved gas measurements in oceanic waters made by membrane inlet mass spectrometry. Limnol. Oceanogr. Methods 3:24-37 [doi:10.4319/lom.2005.3.24]. , and M. C. Long. 2009. Spatial and temporal variability of biogenic gases during the Southern Ocean spring bloom. Geophys Res Lett 36 [doi:10.1029/2008GL035819].

Van Der Laan-Luijkx, I. T., R. E. M. Neubert, S. Van Der Laan, and H. a. J. Meijer. 2010. Continuous measurements of atmospheric oxygen and carbon dioxide on a North Sea gas platform. Atmos. Meas. Technol. 3:113-125 [doi:10.5194/ amt-3-113-2010].

Von Deimling, J. S., G. Rehder, J. Greinert, D. F. McGinnnis, A. Boetius, and P. Linke. 2011. Quantification of seep-related methane gas emissions at Tommeliten, North Sea. Cont. Shelf Res. 31:867-878 [doi:10.1016/j.csr.2011.02.012].

Wankel, S. D., and others. 2010. New constraints on methane fluxes and rates of anaerobic methane oxidation in a Gulf of Mexico brine pool via in situ mass spectrometry. Deep Sea Res. II 57:2022-2029 [doi:10.1016/j.dsr2.2010.05.009].

Wenner, P. G., and others. 2004. Environmental chemical mapping using an underwater mass spectrometer. Trend Anal. Chem. 23:288-295 [doi:10.1016/S0165-9936(04) 00404-2].

Wexler, A. 1977. Vapor-pressure formulation for ice. J. Res. Natl. Bur. Stand. A. 81:5-20.

Submitted 27 September 2011 Revised 14 March 2012 Accepted 6 April 2012 